\title{
An Empirical Study of the Factors influencing Consumer Behaviour in the Electric Appliances Market
}

\author{
Fatimah Furaiji', Małgorzata Łatuszyńska², Agata Wawrzyniak ${ }^{2}$
}

\begin{abstract}
This study contributes to a deeper understanding of the impact of different factors on consumer buying behaviour. It analyses the relationship between several independent variables, such as cultural, social, personal, psychological and marketing mix factors, and consumer behaviour (as the dependent variable) in the electric appliances market.

The purpose of this study is to determine the factors affecting consumer preferences and behaviour in the electric appliances market in Iraq. The data employed to analyse the factors influencing consumers' purchase decision-making processes were obtained through a questionnaire that was conducted in December 2011 in Basra, a city in southern Iraq. The major findings of the study indicated that, overall, the set of independent variables are weakly associated with the dependent variable. However, the in-depth analysis found that social factors, physical factors, and marketing mix elements are strongly associated with consumer buying behaviour. These analyses make it possible to discover consumer decision-making rules. The results may assist producers and retailers in understanding consumer behaviour and improving consumer satisfaction.
\end{abstract}

KEY WORDS: $\quad$ financing structure, selection of financing sources, financial crisis

JEL Classification: D1, M3

${ }^{1}$ Basra University, Iraq

${ }^{2}$ University of Szczecin, Poland

\section{Introduction}

For companies to attain commercial success, it is important that managers understand consumer behaviour. The relationship between consumer behaviour and marketing strategy is emphasised because the success of companies' marketing strategies depends upon managers' understandings of consumer behaviour (understanding of consumer behaviour is especially important during a recession - see Kotler and Caslione (2009). Consumer buying decisions indicate how well

-

Corespondence concerning to this article should be addressed to: mlat@wneiz.pl the company's marketing strategy fits market demand. Thus, marketing begins and ends with the consumer.

The study of customer behaviour is based on consumer buying behaviour, with the customer playing three distinct roles: user, payer and buyer. Research has shown that consumer behaviour is difficult to predict, even for experts in the field (Armstrong \& Scott, 1991). Consumer behaviour involves the psychological processes that consumers go through in recognising their needs, finding ways to solve these needs, making purchase decisions (e.g., whether to purchase a product and, if so, which brand and where), interpret information, make plans, and implement these plans (e.g., by engaging in comparison shopping or actually purchasing a product). 

In the above model, marketing and other stimuli enter the customer's "black box" and produce certain responses. The aim of marketing management is to discover what goes on the in the mind of the customer - the black box. The buyer's characteristics influence how s/he perceives the stimuli; the decision-making process determines what buying behaviour is undertaken. The first step in understanding buyer behaviour is to focus on the factors that determine the buyer's characteristics in the black box model.

Many factors influence a consumer's purchasing decisions and buying behaviour. The literature classifies and structures these factors in various ways (see table 1.). Despite these differences, consumer behaviour is generally influenced by factors that can be classified into five groups: cultural factors, social factors, physical factors, personal factors and the marketing mix. A description of the major factor groups is presented in table 2.

These factors are identified to discover the impacts they have on consumer behaviour and assist marketers with selecting consumer targeting strategy. Therefore, these factors are used to segment the market and target specific consumer groups. The aim of this paper is to understand the influences of the factors that were measured in a survey on purchasing behaviour.

\section{Types of Consumer Behaviour}

Studies suggest that customers generally go through a five-stage decision-making process whenever they make a purchase. This is summarised in fig. 2. The model implies that customers pass through all of the stages in every purchase. However, in more routine purchases, customers frequently omit or reverse some of the stages. The buying process begins with need recognition. At this stage, the buyer recognises a problem or need or responds to a marketing stimulus. Next, the consumer needs to decide how much information (if any) is required to make the decision. If the need is strong and a product or service that meets the need is easily available, a purchasing decision is likely to be made immediately. If this is not the

Table 1. Factors Affecting Consumer Buying Behaviour - Literature Review

\begin{tabular}{ll}
\hline Researcher & Major factors \\
\hline Enis (1974) & personal factors, social factors \\
Cross and Peterson (1987) & social factors, physical factors \\
Dibb and Etal (1991) & personal factors, social factors, physical factors \\
Cohen (1991) & marketing mix, physical factors \\
Zikmond and Amico (1993) & social factors, environmental factors, individual factors \\
McCarthy and Perreault (1993) & physical factors, social factors \\
Narayyana and Raol (1993) & physical factors, social factors, cultural factors \\
Keegan (1995) & social factors, cultural factors, economic factors, geographic factors \\
Setlow (1996) & personal factors, marketing mix, environmental factors \\
Stanton (1997) & social factors, physical factors, attitudinal factors \\
Lancaster and Reynold (1998) & physical factors, social factors, cultural factors \\
Kotler and Armstrong (2007) & physical factors, social factors, cultural factors, personal factors \\
Straughan and Roberts (1999) & demographic factors, lifestyle \\
Pride and Ferrell (2000) & social factors, physical factors, attitudinal factors \\
\hline
\end{tabular}

Note: Own elaboration based on Obaidat, 1995; Stávková, Stejkal, Toufarová, 2008; Suleiman, 2000. 
Table 2. Major Factors Affecting Consumer Behaviour

\begin{tabular}{|c|c|c|}
\hline Major factor & Sub-factors & Description \\
\hline \multirow{4}{*}{ Cultural factors } & Culture & $\begin{array}{l}\text { Factors refer to the set of basic values, wants and behaviours learned by a member } \\
\text { of a society from the family and other important institutions. }\end{array}$ \\
\hline & Sub-culture & $\begin{array}{l}\text { Each culture contains smaller sub-cultures. Sub-culture includes nationalities, } \\
\text { religions, racial groups and geographic regions. }\end{array}$ \\
\hline & Social class & $\begin{array}{l}\text { Society's relatively permanent and ordered divisions, the members of which share } \\
\text { similar values, interests and behaviours. Social class can be determined by a combi- } \\
\text { nation of occupation, income, education, wealth and other variables. }\end{array}$ \\
\hline & Groups & $\begin{array}{l}\text { Group refers to } 2 \text { or more individuals who interact to accomplish individual or } \\
\text { mutual goals. A person's behaviour is influenced by many small groups or reference } \\
\text { groups. These groups involve family, religious groups, friends circle, neighbours etc. }\end{array}$ \\
\hline \multirow[t]{3}{*}{ Social factors } & Family & $\begin{array}{l}\text { Members can strongly influence a buyer's behaviour. Marketers are interested in the } \\
\text { roles and influences of the husband, wife and children on the purchase of different } \\
\text { products and services. }\end{array}$ \\
\hline & Roles \& status & $\begin{array}{l}\text { The person's position in each group can be defined in terms of both role \& status. } \\
\text { Each role carries a status that is conferred by society. }\end{array}$ \\
\hline & Age \& life cycle stage & $\begin{array}{l}\text { People change their purchases over their lifetimes. Marketers define their target } \\
\text { markets in terms of family life-cycle stage and develop appropriate plans and } \\
\text { products for each stage. }\end{array}$ \\
\hline
\end{tabular}

Personal factors

Occupation

Economic situation

Motivation

Psychological factors

Perception

Learning

Product

Price

Marketing mix

Promotion

Placement
A person's occupation affects the goods and services bought.

A person's economic situation affects product choice. Marketers of income-sensitive goods should monitor trends in personal income, savings and interest rates.

When a consumer recognises that they have a need, the inner drive to fulfil the need is called motivation. A motivated person is ready to act.

It is the process by which people select, organise and interpret information to form a meaningful picture of the world.

When people act, they learn. Learning can be described as changes in an individual's behaviour arising from experience.

It is a tangible good or an intangible service that is mass produced or manufactured on a large scale with a specific volume of units.

The price is the amount a customer pays for the product.

It represents all of the communications that a marketer may use in the marketplace. Promotion has four distinct elements: advertising, public relations, personal selling and sales promotion.

A way of getting the product to the consumer and/or how easily accessible it is to consumers.

Note: Own elaboration based on (Hasslinger, Hodzic, Obazo, 2007; Kotler and Armstrong, 2007; Stávková, Stejkal, Toufarová, 2008. 


\begin{tabular}{|c|c|c|c|c|}
\hline $\begin{array}{l}\text { Problem } \\
\text { recognition }\end{array}$ & $\begin{array}{l}\text { Information } \\
\text { search }\end{array}$ & $\begin{array}{c}\text { Evaluation of } \\
\text { alternatives }\end{array}$ & $\begin{array}{l}\text { Purchase } \\
\text { decision }\end{array}$ & $\begin{array}{c}\text { Postpurchase } \\
\text { evaluation }\end{array}$ \\
\hline
\end{tabular}

Figure 2. Consumer Buying Decision Process. Own elaboration based on Pride and Ferrell, 2007; Hansen, 2005

case, the information search process begins. A customer can obtain information from several sources: personal sources (family, friends), commercial sources (advertising, retailers, packaging), and public sources (newspapers, magazines, radio, television, Internet). The usefulness and degree of influence of each of these sources of information will vary by product and by consumer. It is worth noting that marketers today have a greater degree of control over the information that is provided (or is not provided) to consumers and the manner in which this information is presented (Kivetz \& Simonson, 2000).

In the evaluation stage, the customer must choose between alternative brands, products and services. An important determinant of the extent of the evaluation is whether the customer feels "involved" in the product. A buyer's level of involvement determines why s/ he is motivated to seek information about a particular product or brand while virtually ignoring others. The involvement level, as well as other factors, affects an individual's choice of one of three types of consumer buying behaviour: routine response behaviour, limited decision making, and extended decision making (Pride \& Ferrell, 2007, pp. 177-179). Table 3 presents a comparison of the behaviour types.

A consumer uses routine response behaviour when buying frequently purchased, low-cost items that demand very little search-and-decision effort (e.g., milk, eggs, bread or socks). Customers spend very little time deciding whether to purchase these items and do not typically need to read reviews or consult with friends for their opinions before making routine purchases. However, when confronted with 'ethical' products, consumers often become more involved, and this results in a more extensive information search (Carrigan \& Attalla, 2001; Zander \& Hamm, 2011). These are usually small purchases, on the lower end of the pricing spectrum. When buying such items, consumers may prefer a particular brand but are familiar with several brands in the product class and view more than one as being acceptable. Typically, low-involvement products are bought almost automatically.
Limited decision making is a combination of an extensive purchase decision and a routine one. Consumers who participate in this type of buyer behaviour typically know what type of product they want but are attempting to select a brand. Purchasing clothing is a good example of how limited decision making works. A customer who needs a new pair of jeans goes into a store looking for jeans but investigates a variety of brands to determine which pair is the best fit. When customers engage in purchases that require limited decision making, they may seek advice or a suggestion from a friend. This type of decision making requires a moderate amount of time for information gathering and deliberation. The search is not as thorough or as time consuming as it is with higher priced items.

The most complex type of buying behaviour, extended decision making, occurs when purchasing unfamiliar, expensive, or infrequently purchased products (e.g., a computer, television, car or house). Consumers spend substantial amounts of time researching a large number of potential options before they buy. They speak with trusted friends, family, colleagues and sales professionals and read reviews and ratings online and in consumer magazines. Consumers participating in an extended decisionmaking process typically take more time to make a final purchase decision and spend more time researching their options. Many of these consumers experience cognitive dissonance. Extended decision making is frequently used for purchasing high-involvement products.

Purchasing a particular product does not always elicit the same type of problem solving process. Most consumers occasionally make purchases solely on impulse, rather than on the basis of any of these three buying behaviours. Impulse buying is an unplanned decision to buy a product or service, made just prior to a purchase. Such purchases range from small (chocolate, candy, gum) to substantially large (clothes, jewellery, art) and sometimes lead to problems such as financial difficulties, family disapproval, or feelings of guilt or disappointment (Business Dictionary, 2012). For more information on this topic, see Wood (2005). 
Table 3. Comparison between Types of Behaviour

\begin{tabular}{llll}
\hline & Routine response behaviour & Limited decision making & Extended decision making \\
\hline Level of involvement & low & low & high \\
Product cost & low & low to moderate & high \\
Brand preference & $\begin{array}{l}\text { more than one is acceptable, } \\
\text { although one may be preferred }\end{array}$ & several & varies, usually many \\
Search effort & little & little to moderate & extensive \\
Time spent & short & short to medium & long \\
\hline
\end{tabular}

Note: Own elaboration based on Pride and Ferrell, 2007.

\section{A Study of the Factors Influencing Consumer Behaviour in the Electric Appliances Market}

\section{Study Goals and Objectives}

The purpose of this study is to determine the factors that affect consumer preferences and behaviour in the electric appliances market in Iraq. There are few studies related to these products, and this is the first study that has attempted to explore the growing electric appliances market in this country. In Iraq, there are few researchers who are interested in consumer behaviour, and the studies in this area are scarce and inadequate. Researchers working on the topic of consumer behaviour and competition in the Iraqi market are Abo Ahmad (2004), Abood Al-Janabi (2000), Ibrahim and Husin (2009). Furthermore, researchers such as Jtheer, Al-Mosssawi and Hussen study and measure consumer behaviour regarding drugs using a sample of consumers in Baghdad, (Jtheer, Al-Mosssawi, Hussen, 2009).

\section{Study Methodology}

The aim of the survey was to obtain information regarding the influences of the above-mentioned factors (see table 2.) on consumer behaviour when consumers purchase electrical appliances. After completing the literature review, the authors of the paper decided to create a research model (fig. 3.) and implement it to understand and analyse how Iraqi consumers made purchase decisions in the electric appliances market.

The graphical research model can be written in mathematical form. The mathematical model of the research is stated below:
FactorImpactOnBehavior $r_{c, t}=\alpha_{0}+\beta_{1}$ Cultural $_{c, t}+\beta_{2}$ Soc $\mathrm{ial}_{c, \mathrm{t}}+\beta_{3}$ Personal $_{c, t}+\beta_{4}$ Psychological $_{c, t}+\beta_{5}$ Product, $\mathrm{t}+$ $+\beta_{6}$ Price $_{c, t}+\beta_{7}$ Promotion $_{c, t}+\beta_{8}$ Place $_{c, t}+\varepsilon_{c, t}$

where:

$\alpha$ - constant,

$\varepsilon-$ model error,

c-consumer,

$\mathrm{t}$ - making a purchase at a particular time.

The hypotheses formulated after reviewing the relevant literature are presented below:

$\mathrm{H} 1$ : cultural factors have a strong association with consumer behaviour.

$\mathrm{H} 2$ : social factors have a strong association with consumer behaviour.

H3: personal factors have a strong association with consumer behaviour.

H4: psychological factors have a strong association with consumer behaviour.

H5: the product factor has a strong association with consumer behaviour.

H6: the price factor has a strong association with consumer behaviour.

H7: the promotion factor has a strong association with consumer behaviour.

H8: the place factor has a strong association with consumer behaviour.

Tests of the hypotheses were confined to the primary data collected from the area of Basra (the second largest city in Iraq with an estimated population of two million). 


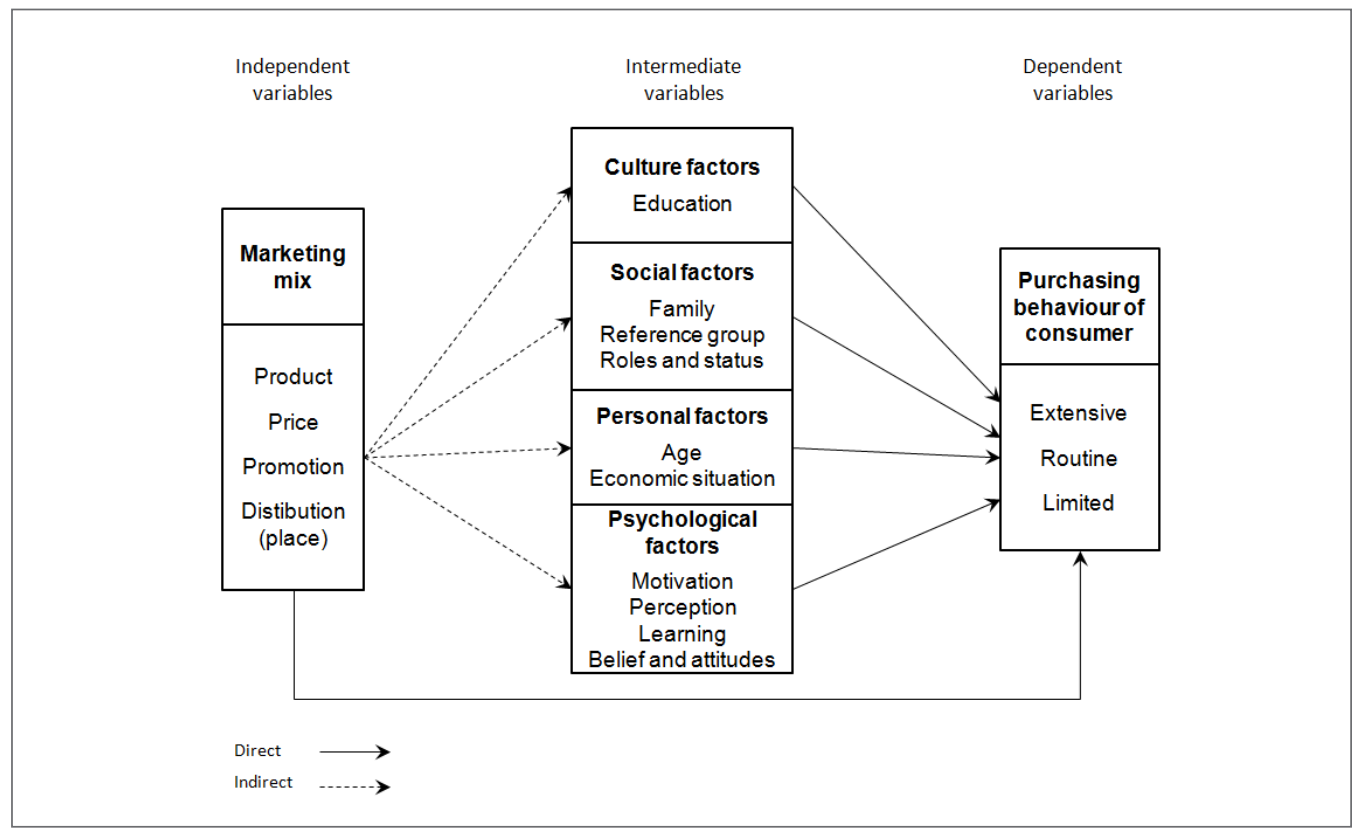

Figure 3. Research Model

\section{Instrument and Study Sample}

The data employed to analyse the factors influencing consumers' purchase decision-making processes were obtained through a marketing survey. The instrument used to collect the primary data was a questionnaire. The authors selected this tool because of its numerous advantages. Because each respondent receives the same questions and an interviewer is not present, the process is identical for each respondent. One advantage of using a questionnaire is that it reduces errors made by an interviewer while recording the responses. Questionnaires guarantee confidentiality; hence, respondents act without any fear or embarrassment. Another advantage is that the interviewer, whose personal appearance, mood or conduct may influence the results of an interview, is not present when the questionnaire is being completed (Burns, 2000, p. 566). Furthermore, a questionnaire is a quick and efficient way to obtain information from a large number of consumers. However, designing a questionnaire is complex and time-consuming, and the quality of the data that are collected is determined by the quality of the questionnaire.

The authors intended that the questionnaire be simple and the questions straightforward and to the point. The questions were divided into three segments as follows:

1. questions on demographic information, including characteristics such as age, education, income, and gender,

2. questions on the factors that impact consumers and consumer behaviour,

3. one question on brand loyalty.

The second part of the questionnaire contained nine sections, and each section represented a variable in the research model (the independent, dependent, and intermediate variables). In this part responses were measured on a 5-point Likert scale, ranging from one (definitely disagree) to five (definitely agree). The third part of the questionnaire contained a single open-ended question about brand loyalty.

The survey was conducted in December 2011 in Basra, a city in southern Iraq, and 200 survey responses were gathered. However, after removing invalid data, 176 correctly completed, acceptable questionnaires remained for the analysis. The data were evaluated using specialised software - the Statistical Package for Social Sciences (SPSS) ver. 17.

Respondents in this study were asked to complete the questionnaire on a voluntary basis. Regarding income, 
$36 \%$ of respondents had monthly incomes in excess of 1 million Iraqi dinars (ID), 43\% had monthly incomes between 500,000 and 999,000 ID and 21\% received less than 499,000 ID per month. Concerning sex, $56 \%$ of the respondents were male and $44 \%$ were female. Of the 176 people who completed our questionnaire, $6.0 \%$ were between the ages of 18-24, 28.5\% were between $25-34,34.0 \%$ were between $35-44,21.5 \%$ were between $45-54$ and 10\% were over 55 years old. Regarding education level, the majority of respondents had received higher education (58.8\%), 21.6\% received secondary education, $12.6 \%$ received intermediate education, 5.0\% received primary education and only $2.0 \%$ have no formal education.

\section{Results and Discussion}

Cronbach's alpha (a measure of internal consistency or how closely related a set of items are) was used to assess the inter-item reliability for each variable. As reported in table 4 , Cronbach's alpha scores were over 0.75 , suggesting that the items have a relatively high degree of internal consistency (note that a reliability coefficient of 0.70 or higher is considered "acceptable" in most social science research (Hair et al., 2006)). These alpha scores are acceptable for an exploratory analysis, indicating that the factors within each variable are inter-related.

Table 4. Reliability Statistics
There was a relationship between each factor and type of consumer behaviour. This operation was divided into two parts as follows:

1. The authors found Pearson's correlation coefficients between the variables associated with questions answered on the Likert scale such as social factors, psychological factors, marketing mix and consumer behaviour. As shown in table 5, the Pearson's $r$ for the correlation between each factor and consumer behaviour was positive. This means that as one variable increases in value, the second variable also increases in value. Similarly, as one variable decreases in value, the second variable also decreases in value. The values of the Person's correlation coefficients in this study were rather low; there is not a strong relationship between the variables. The strongest correlation was between psychological factors and behaviour -0.434 . The significance (2-tailed) values were less than 0.05 . Therefore, we can conclude that there was a statistically significant correlation between each factor and consumer behaviour.

2. To find the relationship between cultural and personal factors and different types of consumer behaviour, a one-way ANOVA was used. Data that represented these factors were divided into three groups: education (a cultural factor), age and

\begin{tabular}{lc}
\hline Variables & Cronbach's Alpha \\
\hline Cultural factors & 0.81 \\
Social factors & 0.83 \\
Personal factors & 0.89 \\
Psychological factors & 0.75 \\
Product & 0.80 \\
Price & 0.79 \\
Promotion & 0.95 \\
Place & 0.83 \\
Routine response behaviour & 0.93 \\
Limited decision making & 0.92 \\
Extensive decision making & 0.95 \\
\hline
\end{tabular}


Table 5. Pearson's Correlation of Variables

\begin{tabular}{lcc}
\hline \multirow{2}{*}{ Variables } & \multicolumn{2}{c}{ Behaviour } \\
\cline { 2 - 3 } Social factors & Pearson's Correlation & Sig. (2-tailed) \\
Psychological factors & 0.299 & 0.000 \\
Product & 0.434 & 0.003 \\
Price & 0.269 & 0.000 \\
Promotion & 0.293 & 0.000 \\
Place & 0.249 & 0.000 \\
\hline
\end{tabular}

Table 6. One-way ANOVA

\begin{tabular}{lcccccc}
\hline Factors & Types of behaviour & SS & df & MS & F & Sig. \\
\hline \multirow{2}{*}{ Education } & Extensive decision making & 1.916 & 4 & 0.479 & 0.764 & 0.550 \\
& Routine response behaviour & 2.309 & 4 & 0.577 & 1.162 & 0.329 \\
& Limited decision making & 17.904 & 4 & 4.476 & 0.750 & 0.559 \\
Age & Extensive decision making & 0.481 & 4 & 0.120 & 0.190 & 0.943 \\
& Routine response behaviour & 0.426 & 4 & 0.107 & 0.208 & 0.934 \\
Monthly & Limited decision making & 12.155 & 4 & 3.039 & 0.509 & 0.729 \\
income & Extensive decision making & 2.584 & 4 & 0.646 & 1.041 & 0.387 \\
& Routine response behaviour & 5.188 & 4 & 1.297 & 2.664 & 0.034 \\
\hline
\end{tabular}

Note: SS - sum of squares, df - degrees of freedom, MS - mean square, F - F ratio, Sig. - significance value.

monthly income (personal factors). The outcome of the ANOVA is presented in table 6. The results reveal that there is not a statistically significant difference between the influences of education and age on consumer behaviour ( $p>0.05)$. Only monthly income has an impact on behaviour, and only under routine response behaviour. In this case, the F ratio is the highest $(\mathrm{F}=2.664)$ and the significance value was below 0.05 (sig. $=0.034$ ).

It was found out that there is a multiple regression between behaviour and all factors. The data presented in table 7 show the results of the multiple regression, which was used to learn more about the relationships between the independent variables and the dependent variable. Testing the previously developed hypotheses developed provided results that made it possible to modify the research model as follows:

FactorImpactOnBehavior ${ }_{c, t}=\alpha_{0}-\beta_{1}$ Cultural $_{c, t}+$ $\beta_{2}$ Social $_{c, t}-\beta_{3}$ Personal $c, t+\beta_{4}$ Psychological ${ }_{c, t}+\beta_{5}$ Product,$t+$ $+\beta_{6}$ Price $_{c, t}+\beta_{7}$ Promotion $_{c, t}+\beta_{8}$ Place $_{c, t}+\varepsilon_{c, t}$

These modifications of the mathematical model indicate that hypotheses 1 and 3 are rejected because the relationships between the variables are weak ( $p>0.05)$. The other hypotheses are accepted based on the strong association among the variables $(\mathrm{p}<0.05)$. Psychological factors strongly affected behaviour. Psychological factors $(\beta=0.43)$ influenced consumer 
Table 6. One-way ANOVA

\begin{tabular}{|c|c|c|c|c|c|c|c|}
\hline \multirow{2}{*}{\multicolumn{2}{|c|}{ Hypothesis \& relationship }} & \multicolumn{2}{|c|}{$\begin{array}{l}\text { Unstandardised } \\
\text { coefficients }\end{array}$} & \multirow{2}{*}{$\begin{array}{c}\begin{array}{c}\text { Standardised } \\
\text { coefficients }\end{array} \\
\text { Beta }\end{array}$} & \multirow[t]{2}{*}{ t-value } & \multirow[t]{2}{*}{ Sig. } & \multirow{2}{*}{$\begin{array}{l}\text { Verification } \\
\text { results }\end{array}$} \\
\hline & & B & Std. error & & & & \\
\hline $\mathrm{H} 1$ & cultural factors $\rightarrow$ behaviour & -0.076 & 0.040 & -0.136 & -1.926 & 0.056 & Rejected \\
\hline $\mathrm{H} 2$ & social factors $\rightarrow$ behaviour & 0.181 & 0.041 & 0.299 & 4.387 & 0.000 & Accepted \\
\hline H3 & personal factors $\rightarrow$ behaviour & -0.055 & 0.031 & -0.123 & -1.738 & 0.084 & Rejected \\
\hline $\mathrm{H} 4$ & psychological factors $\rightarrow$ behaviour & 0.310 & 0.046 & 0.434 & 6.754 & 0.000 & Accepted \\
\hline H5 & product $\rightarrow$ behaviour & 0.179 & 0.046 & 0.269 & 3.924 & 0.000 & Accepted \\
\hline $\mathrm{H} 6$ & price $\rightarrow$ behaviour & 0.142 & 0.033 & 0.293 & 4.303 & 0.000 & Accepted \\
\hline $\mathrm{H} 7$ & promotion $\rightarrow$ behaviour & 0.158 & 0.044 & 0.249 & 3.607 & 0.000 & Accepted \\
\hline H8 & place $\rightarrow$ behaviour & 0.124 & 0.042 & 0.206 & 2.958 & 0.003 & Accepted \\
\hline
\end{tabular}

behaviour more than social factors $(\beta=0.30$ and marketing mix. The relationship between personal factors and consumer behaviour was insignificant, with a $\mathrm{p}$ value of 0.08. A similar result was obtained for the relationship between cultural factors and consumer behaviour $(\mathrm{p}=0.06)$.

\section{Conclusions and Future Research}

This research contributes to the understanding of consumer buying behaviour in the electric appliances market. The major findings of the study indicated that the overall set of independent variables was weakly associated with the dependent variable. However, the in-depth analysis found that social factors, physical factors, and marketing mix elements were strongly associated with the buying behaviours of Iraqi consumers. These analyses make it possible to discover consumer decision-making rules. Moreover, our analysis helped us to identify several promising directions for future research. The primary goal of this future research will be to develop methodological bases for consumer behaviour analysis using Multi-Agent Based Simulation (MABS) and simulation tests using the developed methodology. As a result of our research, we plan to develop a computer simulation model that will allow us to investigate consumer behaviour. The simulation model of the electric appliances market will be elaborated with a multi-agent approach.

\section{References}

Abo Ahmad, R. (2004). Study of Impact of Consumer Behavior and Marketing Mix on Marketing Share for Factory of Soft Drinks. Journal of Kufa Studies, 3, 173-188.

Abood Al-Janabi, T. (2000). Impact of Buyer and Competitive for Determine Marketing Share in Business Companies. (Master's thesis). Al-Kufa: Kufa University.

Armstrong, J. S. (1991). Prediction of Consumer Behavior by Experts and Novices. Journal of Consumer Research, 18(2), 251-256.

Burns, R. B. (2000). Introduction to Research Method. London: Sage Publications.

Impulse buying (2012). In Business Dictionary. Retrieved from http://www.businessdictionary.com/ definition/impulse-buying.html

Carrigan, M., Attalla, A. (2001). The myth of the ethical consumer - do ethics matter in purchase behaviour? Journal of Consumer Marketing, 18 (7), 560-578.

Foret, M., Procházka, P. (2007). Buying Behaviour of Households in the Czech Republic. Agricultural Economics - Czech, 53(7), 318-324.

Hair, J. F., Black, W. C., Babin, B. J., Anderson, R. E., Tatham, R. L. (2006). Multivariate Data Analysis (6th ed.). New York, NY: Prentice-Hall.

Hasslinger, A., Hodzic, S., Obazo, C. (2007). Consumer Behaviour in Online Shopping. Kristiansand: 
Kristiansand University, Department of Business Studies. Retrived from http://www.diva-portal. org/smash/get/diva2:231179/FULLTEXT01

Hansen, T. (2005). Perspectives on Consumer Decision Making: an Integrated Approach. Journal of Consumer Behaviour, 4(6), 420-437.

Ibrahim, H., Husin, W. (2009). The Reality of Social Protection Systems in Iraq and its Impact on Consumer Protection. Iraqi Journal for Marketing Research and Consumer Protect, 1(2), 107-108.

Jtheer, S. H., Al-Mosssawi, M. T, Hussen, J. H. (2009). Measuring Consumer Behavior toward Drugs - Analytical Study for Sample of Consumer in Baghdad. Iraqi Journal for Marketing Research and Consumer Protect, 1(2), 146-180.

Keegan, W., Moriarty, S., Duncan, T. (1992). Marketing. Englewood Cliffs, NJ: Prentice-Hall.

Kivetz, R., Simonson, I. (2000). The effects of incomplete information on consumer choice. Journal of Marketing Research, 37 (4), 427-448.

Kotler, P., Armstrong, G. (2007). Principles of Marketing. Upper Saddle River, NJ: Prentice Hall.

Kotler, P., Caslione, J. (2009). How Marketers Can Respond to Recession and Turbulence. Journal of Consumer Behavior, 8(2), 187-191.

Obaidat, M. (1995). Consumer Behavior. Cairo: The future of publishing and distribution.

Pride, W. M., Ferrell, O. C. (2007). Foundations of Marketing (2nd ed.). Boston, MA: Houghton Miffin Company.

Sandhusen, R. L. (2000). Marketing (3rd ed.). New York, NY: Barron's Business Review Books.

Schiffman, L. G., Kanuk, L. L. (2007). Purchasing Behavior (9th ed.). Upper Saddle River, NJ: Pearson Prentice Hall.

Solomon, M. R. (2004). Consumer Behavior. Buying, Having, and Being (6th ed.). Upper Saddle River, NJ: Pearson Prentice Hall.

Stávková, J., Stejskal, L., Toufarová, Z. (2008) Factors Influencing Consumer Behavior. Agricultural Economics - Czech, 54(6), 276-284.

Suleiman, A. (2000). Consumer Behavior between Theory and Practice. Cairo: The future of publishing and distribution.

Wood, M. (2005). Discretionary Unplanned Buying in Consumer Society. Journal of Consumer Behaviour, 4 (4): 268-281.
Zander, K., Hamm, U. (2011). Information search behaviour and its determinants: the case of ethical attributes of organic food. International Journal of Consumer Studies. doi: 10.1111/j.14706431.2011.00998.x 
87 